\title{
Interseções performativas nos processos de criação de Rodrigo García e Tadeusz Kantor
}

\section{Performative intersections in the creative process of Rodrigo García and Tadeusz Kantor}

Camila Damasceno Silva ${ }^{1}$

Elisabeth Silva Lopes ${ }^{2}$ 


\section{Resumo}

Este artigo apresenta aproximações entre os processos criativos de Tadeusz Kantor e Rodrigo García a partir da perspectiva da dramaturgia performativa. Partindo das indicações cênicas de García descritas em Notas de Cocina e dos escritos de Kantor organizados na coletânea $O$ Teatro da Morte, investigamos os processos criativos do grupo espanhol La Carnicería Teatro para propor um olhar para a dramaturgia enquanto articuladora de processos, discursos, sentidos e sensações, além de catalisadora de materialidades cênicas e imagens poéticas. A articulação que emerge dessa reflexão nos permitirá pensar sobre os modos de operação da dramaturgia no Teatro Performativo.

Palavras-chave: Dramaturgia performativa; processos de criação; Rodrigo García; Tadeusz Kantor

\section{Abstract}

This article presents some relationship between creative process of Tadeusz Kantor and Rodrigo García through the perspective of the performative dramaturgy. From the scenic indications of Garcia described in Notas de Cocina, as well as from the writings of Kantor organized in the selection Theater of Death, we investigate the creative process of the Spanish group La Carnicería Teatro to propose a look for the dramaturgy as an articulator of processes, discourses, meanings and sensations, as well as catalyst of scenic materialities and poetic images. The articulation that emerges from this reflection will allow us to think about how dramaturgy operates in the Performative Theatre.

Keywords: Creative process; performative dramaturgy; Rodrigo Garcia; Tadeusz Kantor

ISSN: 1414.5731

E-ISSN: 2358.6958

1 Doutoranda em Artes da Cena pela Universidade Estadual de Campinas (Unicamp) camila.damasceno@outlook.com

2 Profa. Dra. Com atuação Graduação e no Programa de Pós-Graduação em Artes Cênicas (PPGAC), da Escola de Comunicações e Artes, (USP). bethlopes@ usp.br 
O que o texto suporta.

Descrever um espaço, criar personagens, encher o texto de marcações cênicas: algo que nunca se deveria fazer.

Nesse caso, os nomes que estão junto a cada frase correspondem ao ator para o qual estou trabalhando, em quem penso quando escrevo o texto, isto é: não são personagens, senão pessoas.

Para outro que queira pôr em cena esta obra, os nomes seriam indicativos de quem diz cada parte, ainda que eu não descarte que encontre uma melhor distribuição das frases ou prefira trabalhar com mais ou menos atores.

O mesmo ocorre com o espaço. Tenho que comentar como o imagino, porque senão haveria partes do texto que em vez de sugestões seriam obstáculos para a encenação.

Imagino uma mesa onde se possa cozinhar de verdade, com fogão, cerâmicas, verduras, carnes, óleo e tudo necessário para que cada ator - é importante que a mulher não cozinhe - prepare o prato que mais gosta.

A letra de uma canção de Robert Johnson: "Sweet Home Chicago" aparece no texto porque enquanto os homens cozinham eu gostaria que escutassem esse blues na versão do próprio Johnson (1935).

Também pensei em uma gigantesca reprodução de La Gioconda apoiada no chão. Um objeto de grande presença que não servirá para nada. Em absoluto.

As receitas são atribuídas a Leonardo da Vinci, que foi mestre de banquetes na corte de Ludovico Sforza e proprietário, com Sandro Botticelli, da taberna Os Três Caramujos (García, 2013, p.22) .

Presente na abertura de Notas de Cocina, de 1994, o texto acima é uma das raras indicações cênicas encontradas em toda a obra dramatúrgica de Rodrigo García. Trata-se de uma extensa rubrica reveladora de alguns aspectos importantes dos processos de criação desenvolvidos pelo grupo e, ainda que brevemente, nos aponta pistas concretas sobre a forma como a dramaturgia está presente nos mesmos.

À frente do grupo espanhol La Carnicería Teatro há mais de vinte anos, García (dramaturgo e encenador) propõe um processo de trabalho onde a construção dramatúrgica ocorre concomitantemente à criação cênica, em um fluxo contínuo de produção tanto de materiais textuais, como sonoros, audiovisuais, cenográficos e etc.

\footnotetext{
3 "Lo que el texto aguante.

Describir un espacio, crear personajes, llenar el texto de acotaciones escénicas: algo que nunca se debería hacer.

En este caso, los nombres que hay junto a cada frase corresponden al actor para el que estoy trabajando, en quien pienso cuando escribo el texto, es decir: no son personajes, sino personas.

Para otro que quiera poner en escena esta obra los nombres serán indicativos de quien dice cada parte, aunque no descarto que encuentre una mejor distribuición de las frases o prefiera trabajar con más o menos actores.

Lo mismo ocurre con el espacio. Tengo que comentar cómo lo imagino, porque si no habría partes del texto que en vez de sugerencias serían obstáculos para la puesta en escena.

Me imagino una mesa donde se pueda cocinar de verdad, con fuegos, cacharros, verduras, carnes, aceite y todo lo necesario para que cada actor - es importante que la mujer no cocine - prepare el platô que más le guste.

La letra de una canción de Robert Johnson: "Sweet Home Chicago" aparece en el texto porque mientras los hombres cocinan me gustaría que se escuchara ese blues en versión del propio Johnson (1935).

También he pensado en una gigantesca reproducción de La Gioconda , apoyada e el suelo. Un objeto de gran presencia que no servirá para nada. En absoluto. [...] [...] Las recetas son atribuidas a Leonardo da Vinci, que fue maestro de banquetes en la corte de Ludovico Sforza y propietario, con Sandro Botticelli, de la taberna florentina Los Tres Caracoles". (Tradução nossa).
} 
No presente artigo, discorreremos sobre os aspectos mais relevantes dos processos de criação dos espetáculos da companhia espanhola, partindo das próprias palavras de Garcia, encarando-as como disparadoras para uma reflexão sobre os modos de produção de uma dramaturgia que não se limita à criação de um artefato textual, explorando os caminhos da performatividade em seus procedimentos criativos. Os escritos de Tadeusz Kantor organizados na coletânea O Teatro da Morte nos ajudarão nesta tarefa de forma a nos iluminar o caminho em busca do lugar da dramaturgia no Teatro Performativo, propondo um olhar para a criação dramatúrgica enquanto articuladora de processos, discursos, sentidos e sensações, além de catalisadora de materialidades cênicas e imagens poéticas.

\section{O que o texto suporta.}

Descrever um espaço, criar personagens, encher o texto de marcações cênicas: algo que nunca se deveria fazer.

O que o texto suporta? Que tipo de suporte é um texto? Ou ainda: o quanto um texto pode suportar? Seria de fato essa a função do material textual cênico? Ser suporte das ideias de um autor? Suportar toda a gama de interpretações e percepções de uma obra? Carregar em si integralmente as informações possíveis para que um provável leitor seja capaz de "visualizar" suas cenas? Ser suporte de uma obra teatral que extrapola suas linhas? Estaria a dramaturgia restrita a operação dos significados de um texto, do aspecto semântico das obras teatrais?

Desde meados dos anos 1990, o dramaturgo Rodrigo García tem dado declarações a respeito de sua busca pelo lugar da literatura no teatro. Afirmando-se incapaz de escrever personagens, conflitos e histórias onde ações encaminham o desenrolar de uma trama (García, 2014), o dramaturgo expõe seus textos como materiais abertos a serem manipulados, reordenados, postos em cheque. Escritos em primeira pessoa, são como grandes blocos narrativos de onde emerge um discurso com forte teor autobiográfico, articulando uma infinidade de intertextos a partir de aforismos e declarações quase sempre polêmicas.

No entanto, a palavra nos espetáculos da Carnicería tem um lugar importante não somente enquanto transmissão de uma informação ou como discurso do autor, mas ainda como materialidade, como coisa física, capaz de ser manipulada, repartida, embaralhada e reordenada conforme a intensão de causar sensações diversas nos atuantes e espectadores.

Ao longo do percurso do grupo, Rodrigo e a Carnicería experimentaram diversas maneiras de se relacionar com a materialidade das palavras. Hora ditas pelos atores em cena, hora projetadas sobre um cenário, hora reproduzidas em áudios prégravados, hora sendo estampadas em camisetas, hora sendo distorcidas através de dispositivos sonoros. "Fui percebendo que quanto menos massa textual aparecia nas obras, mais importância tinham as palavras, mais possibilidades tinha de experimentar e me recriar na minha escrita [...]"4 (Ruiz; Hernández, 2008, p. 3). Em todas as obras

\footnotetext{
4 "Me fui dando cuenta que cuanto menos masa textual aparecía en las obras, pues más importancia tenían las palabras y más posibilidades tenía de experimentar y recrearme en mi escritura [...]". (Tradução nossa).
} 
do grupo é possível perceber um trabalho com o aspecto material, sonoro, rítmico em paralelo ao aspecto interpretativo.

Desta forma, o que a Carnicería explora em cena está além do contato direto entre autor e público/leitor ou um contato intermediado por atores. A performance da palavra expõe uma tensão entre os aspectos semânticos e não-semânticos da obra, explorando uma camada não-hermenêutica do texto, no qual, nem sempre, o sentido é a dimensão predominante. O apelo à camada não interpretativa está presente principalmente nesta materialidade textual que se dá nas alternativas de construção cênica propostas por García. A palavra nos espetáculos do La Carnicería é mais do que um discurso organizador dos aspectos de sentido da obra, mas é em si acontecimento.

O encenador polonês Tadeusz Kantor, por sua vez, relata - a respeito de seu processo criativo junto ao Teatro Cricot $^{2}$ - um "esforço empreendido com o objetivo de criar novas relações com o texto". Para Kantor, o texto literário é um "objeto pronto", formado fora da esfera do espetáculo. "Ele é 'objeto encontrado' condensado ao mais alto grau, que possui sua própria ficção, sua ilusão, seu espaço psicofísico" (Kantor, 2008, p.140), devendo então ser submetido à mesma "lei" dos outros acontecimentos e objetos do espetáculo. De forma similar ao que Kantor propõe, nos espetáculos do La Carnicería, as imagens cênicas, os cenários, os jogos dos atores, os efeitos audiovisuais, sonoros e de iluminação não estão em favor de um texto, mas estabelecem, juntamente com o mesmo, um processo de produção de sentido e presença, um discurso da cena, mas também uma camada não discursiva explorada principalmente através das corporeidades dos performers.

II. Os nomes que estão junto a cada frase correspondem ao ator para o qual estou trabalhando, em quem penso quando escrevo o texto, isto é: não são personagens, senão pessoas.

Assumir que os textos são escritos para aqueles atores específicos e indicar seus nomes antes das "falas" revela tanto uma construção dramatúrgica concomitante à criação cênica como um todo, quanto um caráter performativo que se busca na atuação. Com fortes referências autobiográficas, os textos já expõem um embate entre ficção e realidade. O que García propõe é que sejam ditos a partir de um repertório do ator enquanto pessoa, com suas contradições, crenças e visões de mundo anteriores à construção da obra. A proposta é não se apoiar na criação de um ser ficcional/personagem que possibilite o deslocamento do que pensa e sente o ator/a atriz em prol de um ser imaginário. Em todo caso, não se exclui uma camada ficcional ou representativa, mas o foco estaria voltado para a presença destas determinadas pessoas em cena.

Neste aspecto, Rodrigo García assume postura semelhante à ideia de Tadeusz Kantor de "zona de pré-existência" do ator. No texto "Método da Arte de ser Ator", Kantor discorre a respeito do que percebe como "predisposições elementares" do ator; individuais, específicas e "primeiras", algo que preexiste ao trabalho cênico e que diz respeito ao repertório prévio de cada um. Seriam estas pré-disposições elementares o motor de uma qualidade de real na cena do grupo. "O ator não representa 
nenhum papel, não cria nenhuma personagem, nem a imita, ele permanece antes de tudo ele mesmo, um ator carregado de toda essa fascinante bagagem de suas predisposições e de suas destinações" (Kantor, 2008, p. 136). Para tanto, Kantor defende, então, o desenvolvimento de um "espírito de equipe" que, associado à consideração de tais "predisposições preliminares", fomenta a autonomia da criação artística e o estabelecimento de uma "zona livre da arte do ator". Aqui, mais uma vez, os procedimentos de trabalho adotados nos dois coletivos se mostram semelhantes.

Em entrevista aberta na Mostra Internacional de Teatro de São Paulo (2014), Rodrigo García diz que o trabalho com os atores - aos quais chama de "companheiros de uma viagem intelectual e cotidiana" - é sempre o ponto de partida para suas criações e define como fator mais importante no processo a cumplicidade que se estabelece entre eles. "Só posso pedir (essa cumplicidade) a determinadas pessoas porque compartilham comigo certa filosofia que vai muito além do teatro". (García, 2014).

A preocupação primeira em estabelecer o que Kantor trata como "espírito de equipe", afeta diretamente o processo de criação de García junto ao coletivo. Na proposição de uma forma de trabalho onde prevaleça este espírito - fomentado por uma não-hierarquização de funções ou saberes - proporcionando a autonomia dos artistas envolvidos e a liberdade criativa de cada componente do grupo, o dramaturgo se insere no processo de construção da obra de forma ativa e presente. Em entrevista publicada no catálogo de Gólgota Picnic, em 2010, ele revela resumidamente o trajeto que percorreu até encontrar este modo de criação.

\begin{abstract}
No início, há mais de quinze anos, seguia um processo normal, como qualquer dramaturgo; escrevia as obras e depois as montava. Depois fui mudando a metodologia do trabalho. Existe uma grande diferença entre o escrito e o que se escuta; o texto geralmente é bastante frustrante, com muitas coisas que não funcionam. De fato, segundo o meu gosto, noventa por cento do teatro não funciona, são coisas que não compreendo, anacrônicas, como uma espécie de maquinaria que não anda. Eu me questionei sobre essas coisas e pensei que era melhor fazê-lo todo desde dentro, desde o teatro, isso é, como se fosse uma obra arquitetônica na qual juntamos várias pessoas, vamos gerando materiais e vemos se aquilo é consistente para que as ideias tenham sua própria existência. Trata-se de materializar essas ideias e a melhor forma de conseguir isso, já que trabalhamos com teatro, é estar junto a outras pessoas e ir construindo [...] (Vera, 2010, p. 9) .
\end{abstract}

Esta noção de obra teatral como obra arquitetônica, na qual o dramaturgo/encenador lida com as materialidades cênicas para erguer o trabalho em conjunto com a presença essencial dos atores é base do processo de criação da companhia espanhola, embora, assim como Tadeusz Kantor, haja uma ressalva quanto ao aspecto improvisacional que tal proposição aparenta ter. Para o encenador polonês, o que chama "zona livre da arte do ator" não deve ser confundido com a improvisação, pois "as práticas e as atividades dos atores possuem a estrutura e a textura dos happenin-

\footnotetext{
5 "Al principio, hace más de quince años, seguía un proceso normal, como cualquier dramaturgo; escribía las obras y luego las montaba. Después fui cambiando la metodología de trabajo. Hay mucha diferencia entre lo escrito y lo que luego se ejecuta; el texto suele ser bastante frustrante, con muchas cosas que no funcionan. De hecho, según mi gusto, el noventa por ciento del teatro no funciona, son cosas que no comprendo, anacrónicas, como una especie de maquinaria que no marcha. Yo me cuestioné esas cosas y pensé que era mejor hacerlo todo desde dentro, desde el teatro, es decir, como si fuera una obra arquitectónica en la que nos juntamos varias personas, vamos generando materiales y vemos si aquello es consistente para que las ideas tengan su propia existencia. Se trata de materializar esas ideas y lo mejor para conseguirlo, ya que trabajamos en teatro, es estar junto a otras personas e ir construyendo [...]". (Tradução nossa)
} 
gs. Elas abarcam toda realidade, as coisas, as situações e as pessoas" (Kantor, 2008, p. 136).

No trabalho do La Carnicería, este aspecto improvisacional está presente em menor medida nas apresentações, mas é ponto de partida dos processos de criação. Para Rodrigo García é importante frisar que a estrutura das obras não deixa espaços à improvisação em cena: "É uma estrutura totalmente rígida, totalmente medida, que tem suas próprias leis muito calculadas; dentro disso, a forma de movimentar-se parece que é muito livre, mas não cabe a improvisação, de nenhuma forma"6 (Diago, 2002 , p. 1). Desta forma, a prática da improvisação nos trabalhos do grupo estaria mais próxima da ideia de improvisação enquanto método, explorada na geração de materiais e não a serviço dos mesmos. Um tipo de improvisação que se torna o meio através do qual os materiais são produzidos, gerando narrativas não lineares e diferentes tipos de seres ficcionais (Bonfitto, 2009). A improvisação enquanto método, neste sentido, é um dos aspectos mais importantes dos processos de criação da Carnicería. Segundo relatos dos integrantes do grupo, os momentos de criação se concentram principalmente no trabalho com as materialidades da cena. Os ensaios transcorrem a partir de proposições de García. Os estímulos partem de comandos que buscam ser claros e precisos, porém deixando brechas para a criação dos atores; comandos como: "pulem como jovens em shows de rock" ou "sapateie em cima da mesa". A cada dia se criam novas ações, imagens, movimentos sem que sejam repetidos até que o dramaturgo proponha as primeiras possibilidades de ordenação dos fragmentos (García, 2015). Para García as possibilidades que se criam não se dão somente direcionadas por seus estímulos, mas também porque são preenchidas por um trabalho próprio dos atores. "[...] sobretudo, é importante trabalhar com pessoas que não tenham medo, que não tenham pudor"

Desta forma, é a partir da improvisação enquanto método, semelhante ao processo descrito por Bonfitto, que se criam os materiais cênicos e textuais que serão reordenados em um processo de composição, um segundo momento da criação dramatúrgica, que inclui a ordenação dos quadros/cenas em uma espécie de storyboard teatral que expõe as fricções entre as materialidades da cena. Fricções que o texto não necessariamente produz.

\section{Para outro que queira pôr em cena esta obra...}

Rodrigo García não exclui a possibilidade de serem encontradas outras formas de dizer seus textos e inclusive que estas sejam mais potentes do que suas escolhas. Mas sua postura diante do material textual que produz propõe um modo de trabalho que considere o texto como objeto cênico. Ou como diz Kantor (2008): “objeto pronto", encontrado.

É nesta condição de "objeto encontrado" que García parece colocar seus textos quando se refere ao uso futuro dos mesmos por outros encenadores ou coletivos, considerando que introduziriam este material em processos diversos de criação. No

\footnotetext{
6 "Es una estructura totalmente rígida, totalmente medida, que tiene sus propias leyes muy calculadas; dentro de eso la forma de moverse parece que es como
} muy libre, pero no cabe la improvisación, de ninguna manera". (Tradução nossa) 
entanto, por não se tratarem de textos que buscam serem suportes das obras cênicas para as quais foram escritos, uma postura de "montagem" destes textos não é capaz de acessar as fricções propostas pela cena do grupo. Diante disto, que tipo de dispositivo pode ser criado para que a encenação destes textos mantenha latente tais fricções? O que acontece com o discurso de García quando descolado das imagens com as quais conviveu na cena do La Carnicería? O que acontece com um texto seu quando posto em cena a partir da ideia de um teatro de caráter fortemente representacional?

Os processos de criação do coletivo espanhol preveem a construção dramatúrgica concomitantemente à criação cênica. "Os ensaios nunca são uma repetição de coisas, mas momentos de criação. Cada ensaio é uma experiência, uma descoberta de materiais", diz John Romão (assistente de direção) ${ }^{7}$, relatando mais uma similaridade aos processos do Teatro Cricot $^{2}$, onde os ensaios não existiam exclusivamente para a montagem de um espetáculo, mas como momentos de criação. "A estrutura do Teatro Cricot $^{2}$ coloca em princípio que o trabalho no teatro deve ser criação. Ela abole a separação artificial e rigorosamente obrigatória entre em trabalho e resultado, em ensaios e espetáculo" (Kantor, 2008, p. 180).

Considerando o processo de criação do grupo como um fluxo de criações mútuas (não só de atores e dramaturgo, mas de sonoplastas, iluminadores, vídeo criadores e etc.), o uso do material textual em outros processos de criação distintos, "para outro que queira pôr em cena esta obra", projeta também outras formas de trabalho com o texto, que não contemplam seu processo de criação/composição.

IV. Imagino uma mesa onde se possa cozinhar de verdade, com fogão, cerâmicas, verduras, carnes, óleo e tudo necessário para que cada ator [...] prepare o prato que mais gosta.

Óscar Cornago, ao comentar o cenário de "Versus", obra do La Carnicería produzida em 2008, afirma que este se constrói como um lugar de exposição, de fragilidade e de "tempo de jogo" (Cornago, 2008). A distância de quatorze anos entre as produções de "Notas de Cocina" e "Versus" revela a reiteração deste modo de construção da cena, que busca criar condições para uma ação real e uma atmosfera que proporcionem desafios aos atores, que sejam propícias ao alcance de um estado de presença e de criação de corporeidades singulares.

Tadeusz Kantor, ao escrever a respeito da encenação de "O Retorno de Ulisses", afirma que a renúncia aos cenários tradicionais não se dá por razões formais, "há razões mais importantes" e continua: "Em seu lugar virão formas que exprimirão a constituição da ação, seu curso, sua dinâmica, seus conflitos, [...] que criarão tensões, que engajarão o ator [...]" (Kantor, 2008, p. 9). Aqui, mais uma vez, os elementos cênicos são criados para garantir condições à manutenção de um sistema de tensões que funda a cena. Propondo ao público um deslocamento de uma concepção tradicional de teatro, o expondo a um fluxo de percepções flutuantes entre o real e o ficcional

${ }^{7}$ Declaração feita em curta entrevista realizada no Teatro Sesc Vila Mariana, no dia 15 de março de 2014. 
da obra, os cenários não se constroem como ambientações, mas como dispositivos cênicos capazes de estimular estados psicofísicos nos atores.

Manter um ator cozinhando, preocupado para que não queime o azeite, me dá um efeito de realidade e liberdade, porque o ator está tão ocupado em sua ação real de cozinhar, nessa realidade do que está fazendo, que já não tem que preocupar-se com interpretar, simplesmente tem que fritar um ovo, se preocupar com fazer a carne... (Diago, 2002, p. 1) . $^{8}$

Artifício de encenação que desloca a atuação, retirando-a de um estado meramente representacional, o cenário real da cozinha exige do ator atenção e prontidão em cena. Propicia uma ação que favorece o estado de presença propondo corporeidades distintas e conflitantes em constante fricção com os demais elementos da cena (texto, música, iluminação).

Instaura uma perspectiva de jogo que restitui aos objetos seu uso comum. Desestabiliza a relação com o tempo ao possibilitar a coexistência cênica de um tempo ficcional, um tempo cronológico e o tempo da experiência. Apresenta-se como fator primordial na construção de um tipo de cena que busca instaurar um acontecimento. Um tipo de teatro que joga com uma "multiestabilidade perceptiva", uma oscilação na percepção do espectador que hora vê o corpo fenomenológico do ator, hora os signos que compõem o corpo ficcional, garantindo que nem "representação" nem "presença" estabilizem-se permanentemente (Fischer-Lichte, 2008). A criação de dispositivos que permitam essa fricção constante entre real e ficcional, entre presença e representação, no entanto, dirige-se tanto ao público quanto aos performers e está presente em todas as camadas que permeiam a cena.

V. A letra de uma canção de Robert Johnson: "Sweet Home Chicago" aparece no texto porque enquanto os homens cozinham eu gostaria que escutassem esse blues na versão do próprio Johnson (1935).

Sweet Home Chicago é um blues de 1935 de melodia fácil (reproduzida em diversas outras canções da mesma época) e está presente no repertório de grandes intérpretes como Eric Clapton, Budd Guy e Blues Brothers. Até o ex-presidente Barack Obama tem sua versão para a canção de Robert Johnson. Mas García faz um pedido: enquanto os homens cozinham eu gostaria que escutassem esse blues na versão do próprio Johnson. Uma escolha de gosto pessoal? Talvez. Ou a versão repleta de ruídos das gravações em vinis traria outros elementos sonoros que García acredita ter importância para a geração da atmosfera da cena? Fato é que a presença da música nas obras da Carnicería é sempre marcante. Com repertório que vai de canções pop como Me gusta la Gasolina, passando por Cálice, de Chico Buarque e uma versão um tanto cínica de Nick Cave e Shane McGowan para What a wonderful world, até trechos de sinfonias de Bach e As sete últimas palavras de Cristo na Cruz, de Joseph

\footnotetext{
8 "Mantener a un actor cocinando, preocupado porque no se queme el aceite, me da un efecto de realidad y libertad, porque el actor está tan ocupado en su acción real de cocinar, en esa realidad que está haciendo, que ya no tiene que preocuparse por interpretar, simplemente tiene que freír un huevo, cuidar de que se haga la carne...." (Tradução nossa)
} 
Haydn, executada em sua totalidade durante o espetáculo Gólgota Picnic pelo pianista Marino Formenti.

Não são poucos os espetáculos do grupo onde há música sendo executada ao vivo no palco. Dentre muitos exemplos, em "Versus", uma banda de Heavy Metal está presente, em "Compré uma pala em Ikea..." a cantora flamenca Anna María Hidalgo divide o palco com os atores e em "Cruda, vuelta y vuelta, al punto, chamuscada", "murgueros" argentinos, mais que músicos, são personagens da obra, narrando momentos autobiográficos mesclados a textos construídos por García.

As sonoridades, para além da música - como os ruídos que se embaralham em momentos de forte incômodo para o público em "After Sun" ou o som do vento em alto volume, durante o salto de paraquedas de Núria Lloansi em "Gólgota Picnic"- são parte importante dos materiais que a Carnicería compõe. Muitas vezes servindo para instaurar quebras entre os fragmentos cênicos, proporcionam não somente a desestabilização sensorial do espectador, mas possíveis chaves de leituras e ressignificação dos signos dos espetáculos.

VI. Também pensei em uma gigantesca reprodução de La Gioconda apoiada no chão. Um objeto de grande presença que não servirá para nada. Em absoluto.

A primeira questão que se apresenta a partir da indicação de García diz respeito à definição de que a reprodução seja de La Gioconda, obra facilmente identificável com o artista que a produziu e ao qual há uma referência explícita neste trabalho do grupo - Notas de Cocina é também o nome da publicação que reúne as receitas de Leonardo Da Vinci que serão preparadas pelos atores.

Caberia, neste momento, uma longa análise das possíveis leituras que uma reprodução da Monalisa (em tamanho muito maior do que o original) pode encadear, indicando, logo de partida, que não se trata de uma mera citação. Cada uma das possíveis leituras que se faz da obra de Da Vinci poderiam abrir ainda mais caminhos distintos para reflexão. No entanto, em concordância com os aspectos que analisamos até aqui, não nos parece que a dimensão interpretativa seja o alvo desta escolha. A relação com os objetos nas cenas da Carnicería escapam a uma condição de "objetos cênicos", com funções ficcionais ou decorativas, muitas vezes flertando com a noção de readymade, ou, como diria Kantor, objeto pronto.

Para o encenador polonês, o teatro deveria estreitar sua relação com as questões propostas pelas artes visuais, tanto em relação à representação, quanto à sacralização do artista e do objeto de arte, encarando uma ruptura com a institucionalização ao modelo dadaísta. Daí a proposta de lidar com os objetos presentes na cena tal como com readymades. Para Tadeusz Kantor (2008, p. 190), "A obra de arte, fechada em sua estrutura, resultado da criação, da expressão interior, da representação única, isolada e, finalmente, institucionalizada - tornou-se o obstáculo principal, a barreira a transpor". Daí que a presença de uma grande reprodução de La Gioconda em cena pode indicar, mais do que um "objeto inútil", um dispositivo que possibilite a fricção entre o caráter efêmero da "Notas de Cocina" de García e a perenidade da obra pictórica de Da Vinci. 


\section{Processualidade e urgência}

Em 2002, o jornalista espanhol Pablo Caruana acompanhou parte do processo de criação do espetáculo Compré una pala en lkea para cavar mi tumba e fez uma série de publicações contendo relatos de momentos dos ensaios, entrevistas com os integrantes do grupo e com espectadores na saída do teatro após as apresentações. A seguir veremos parte do relato de García sobre um momento específico do trabalho:

Agora estamos lendo os textos e vamos vendo o que nos faz "tilín" e o que não. Ler, ler, ler e sobre tudo ver como coloca-los. [...] Precisa ter um "feeling" muito rápido e ser consciente dos recursos que cada um tem. Temos um montão de ações com muito pouco texto. Assim, vou seguir um esquema similar ao de Conocer gente, comer mierda - obra em que os atores diziam o texto, por exemplo, enquanto se esbofeteavam. Tenho pensado em meter um bloco de textos muito reconhecível, não espalhá-los pela obra toda. [...] quero meter um texto no início, para aproveitar as fotos que temos feito para apresentar a obra, onde se vê os atores com cartões de crédito e euros cravados em suas cabeças. Quero começar a obra assim [...]. Hoje, temos que fazer duas coisas: Primeiro, os aforismos; temos algo entre 60 e 80 aforismos; realmente, mais de cinquenta por cento é ruim, mas dos outros cinquenta por cento que não está tão ruim, é preciso jogar fora a metade [...]. Isso é uma coisa. Depois, está o texto do Rubén [adolescente de doze anos que atuou na peça] que eu estou gostando cada vez mais... [no texto, o menino fala de seus planos para o futuro]. Tenho que falar com ele, ver até onde chega; eu acredito que vai chegar e com segurança, acredito que é possível (Caruana, 2002, p.10) ${ }^{9}$.

Este breve relato revela o que parece ser a principal característica dos processos de criação do La Carnicería: a prontidão para a produção constante de materiais (inclusive textuais). A maneira como o dramaturgo se insere nesse processo possibilita que o material cênico esteja sempre em constante transformação.

Para García, cada processo tem seus procedimentos específicos, mas o determinante no trabalho do grupo é não falar dos "porquês" de cada coisa. "Se se racionaliza o trabalho, se perde o mistério" (Santillán, 2009, p.90) ${ }^{10}$. Mas seria apenas o mistério, o fazer "tilín" ou o "feeling" do dramaturgo os responsáveis pelas escolhas que faz? A reflexão que desenvolvemos até aqui indica que, mais do que um "feeling", a atitude diante dos materiais produzidos e a disponibilidade constante para mergulharem nos possíveis desdobramentos destes são determinantes para o tipo de criação que propõem. Tal prontidão, contudo, está diretamente relacionada a um aspecto constante no trabalho do grupo: a urgência.

Muitas obras do La Carnicería foram produzidas para festivais em toda a Europa. A História de Ronald..., para o Festival CITEMOR, de Portugal; Versus, para o XXIII Festival Iberoamericano de Cádiz, na Espanha; Esto es así y a mí no me jodáis, para o Fes-

\footnotetext{
9 "Ahora estamos leyendo los textos y vamos viendo qué nos hace "tilín" y qué no. Leer, leer, leer y, sobre todo, ver como colocarlos. [...] Tiene que haber un "feeling" muy rápido y ser consciente de los recursos que uno tiene. Tenemos un mogollón de acciones con muy poco texto. Así que voy a seguir un esquema similar a Conocer gente, comer mierda - obra en que los actores decían el texto, por ejemplo, mientras se pegaban galletazos -. He pensado en meter un bloque de textos muy reconocible, no desperdigarlos por toda la obra. [...] Luego me gustaría meter un texto al principio, para conservar las fotos que hemos hecho para presentar la obra, donde se ve a los actores con tarjetas de crédito y euros clavados en sus cabezas. Quiero empezar la obra así [...] Hoy tenemos que hacer dos cosas. Primero, los aforismos; hay como 60 u 80 aforismos; realmente, más del 50 por ciento es malo, pero del otro 50 por ciento que no está mal hay que quedarse con la mitad. [...] Eso es una cosa. Y luego, está el texto de Rubén, que cada vez me está gustando más... Hay que hablar con él, ver a qué llega; yo creo que va a llegar y que seguro, que es posible". (Tradução nossa)

10 "Si se racionaliza el trabajo, se pierde el misterio". (Tradução nossa).
} 
tival Kustenfestivaldeasrts, da Bélgica; After Sun, para o Festival de Delfos, na Grécia; dentre outras mais. $O$ que todas essas produções têm em comum é um tempo muito reduzido entre o início do trabalho e a data da estreia. Desta forma, a prontidão, a urgência, a disponibilidade e a processualidade (ou atitude de constante estado de criação) são aspectos que se mostram determinantes para o tipo de trabalho que o La Carnicería desenvolve.

\section{Conclusão}

Ainda que sejam autônomos, sem necessidade de complementação na cena para que gerem sentidos múltiplos, os textos dramatúrgicos de García não dão conta - nem se propõem a dar - do todo de suas obras, pois a dimensão semântica não é o único nem principal aspecto comunicativo delas. Existe no trabalho da Carnicería um aspecto não semântico, um dado de percepção, que não é apreendido pela criação literária e que se potencializa justo na fricção entre as camadas de sentido e de presença, entre materialidades e discursos. A escolha por começar os processos a partir dos materiais e dos corpos já inaugura um lugar de desestabilização do aspecto interpretativo. Desloca as sensibilidades e propõe um modo de operar que considera a realidade física das coisas do mundo, buscando potencializar as possibilidades de acessar o espectador através do que é material, palpável.

A dupla condição de García enquanto dramaturgo e encenador gera questões a respeito das competências que o dramaturgo inserido em um processo performativo necessita desenvolver. Uma perspectiva total da cena parece ser a primeira delas, seguida da capacidade de ordenar fragmentos considerando não somente um encadeamento que gere sentidos, mas também as possibilidades de sucessões de estímulos sensoriais e as fricções possíveis entre todas as materialidades cênicas, desde os corpos dos atores, aos objetos, luzes, sons, espaços e textos. Por fim, a exploração da materialidade das palavras no espaço e nos sons a partir de imagens e vozes.

A perspectiva dos processos de criação e do que chamei de processos de composição dá a ver uma atuação do dramaturgo como um arquiteto de materialidades, estimulando a criação dos atores, criando ele mesmo esboços de possibilidades de movimentações e imagens, além dos textos que compõe e dos storyboards que ordenam os fragmentos, como uma maquete que servirá de base para o erguimento da obra. A construção de uma dramaturgia performativa parece então passar por uma atitude do dramaturgo que não se detém à criação de um texto para a cena ou de uma "ideia de encenação", mas trabalha principalmente no desenvolvimento de uma escritura que diz respeito a um campo de mediações intertextuais. Esta mediação não se revela, no entanto, como busca por um apaziguamento ou equilíbrio das relações. Pelo contrário, movimenta um sistema de tensões e resistências que acentua a dimensão performativa através do trabalho com as materialidades, do sentido processual da obra, de seu caráter de imediatez e da comunicação sensorial com o público que gera um sentido de coletividade (Cornago, 2006).

Esta busca por acessar uma multiestabilidade perceptiva tanto no público quanto nos atuantes é talvez o disparador das semelhanças entre os processos de Kantor e García e fundador das características performativas de ambas as obras. É ela que 
impulsiona a exploração de múltiplos dispositivos capazes de gerar uma zona de instabilidades aos próprios performers e, consequentemente, ao público.

As reflexões traçadas no presente trabalho nos impulsionam no sentido da construção de um olhar para os procedimentos dramatúrgicos enquanto articuladores de processos, discursos, sentidos e sensações. Uma dramaturgia que se apresenta como catalisadora de materialidades cênicas e imagens poéticas. Um modo de estar no mundo e nos processos que não se limita a criação de uma materialidade textual centralizadora.

\section{Referências}

BONFITTO, Matteo. A Cinética do invisível. São Paulo: Perspectiva, 2009.

CARUANA, Pablo. Entrevista con Rodrigo García y los actores de La Carnicería. Madrid: Primer Acto, n²94, 2002.

CORNAGO, Óscar. Cuerpos, politica y sociedad: una cuestión de ética. In: Juan Domínguez, Marta Galán, Fernando Renjifo. Éticas del cuerpo. Madrid: Fundamentos, 2008, p. 50-83.

Teatro postdramático: Las resistencias de la representación. In: SÁNCHEZ, José Antônio (dir.), Artes de la escena y de la acción em España 19782002. Cuenca: UCLM, 2006b, pp.165-179.

DIAGO, Nel. Conversando com Rodrigo García. Los limites del teatro. El teatro y sus limites. In: Stychomytia Revista de Teatro Español Contemporáneo, n 0: Valencia, 2002.

FISCHER-LICHTE, Érika. The Transformative Power of Performance: A New Aesthetics. Londres: Routledge, 2008.

GARCÍA, Rodrigo. Cenizas Escogidas. Segóvia: La Uña Rota, 2013.

Rodrigo García e John Romão (Carnicería Teatro/ Gólgota Picnic). Itaú Cultural: São Paulo, 14 de março de 2014. MITsp, vídeo de 1h04, 2014. Disponível em: https://www.youtube.com/watch?v=1gxjtHIOOIA. Acesso em: 12 jan. 2015.

Entrevista concedida a Autora, Hotel Ibis Bogotá, 25 de setem-

bro de 2015.

KANTOR, Tadeusz. O Teatro da Morte. Organização Denis Bablet. São Paulo: Perspectiva, 2008.

RUIZ, Mercedes; HERNÁNDEZ, Yohayna. Pero hay que hacerlo, si no, qué gracia tiene. 
Una charla con Rodrigo García. ARTEA: Investigación y Creación Escénica: Madrid, 2008.

SANTILLÁN, Juan José. Labia afilada y ajuste de cuentas. Madrid: Revista Conjunto. 151-152, pp.82-90, 2009.

VERA, Gerardo. Cuaderno Pedagógico 51. Centro Dramático Nacional: Teatro María Guerrero. Madrid, 2010.

Recebido em: 28/04/2017 Aprovado em: 23/06/2017 